\title{
Food Safety Compliance and Challenges of Micro Food Business Operators: Implications to COVID-19 Pandemic
}

\author{
Lea B. Milan ${ }^{1 *}$, Abegail F. Feliciano ${ }^{2}$, and Aljon N. Lusong ${ }^{3}$ \\ 1,2,3 Tarlac State University Lucinda Extension Campus, Tarlac City, Philippines \\ 'https://orcid.org/0000-0001-9591-3862, 2https://orcid.org/0000-0002-7818-8897, \\ 3https://orcid.org/0000-0002-2254-3212 \\ *Email Correspondence: Ibmilan@tsu.edu.ph
}

\begin{abstract}
The food safety compliance and challenges of micro-Food Business Operators (FBOs) that could impact COVID-19 are assessed in this study using the descriptive-comparative research design. The findings reveal that the sanitary conditions of utensils and equipment, the sanitary operations and facilities, the monitoring of time and temperatures, and the maintenance of the sanitary conditions in the facility need major improvement to increase food safety compliance and to contribute in mitigating the transmission of COVID-19. Minor improvements are needed in the handwashing facility, the implementation of the water potability program, Sanitation Standard Operating Procedures, personnel disease control, and hygienic practices. Moreover, the lack of technical knowledge and time to manage and continuously improve food safety system are the challenges experienced by the FBOs. These findings are instrumental to the improvement of the food safety practices, formulation of relevant policies, and conceptualization of research in mitigating COVID-19 relevant to food safety.
\end{abstract}

Keywords: food safety audit, COVID-19, food safety problems, impact of COVID-19, food safety during pandemic

\subsection{Introduction}

The increasing trend in the global human population which is expected to reach almost 10 billion by 2050 (United Nations, 2019) provides increasing challenges for the availability of safe, nutritious, and healthy food for the people (Garcia et al., 2020). The World Health Organization (WHO, 2021) estimated about 600 million cases of foodborne diseases and 420000 deaths annually caused by consuming unsafe foods.

Regulations and laws that use mandatory standards which are monitored and implemented by state agencies and the voluntary standards defined by market laws or international associations are the two systems being used in the food supply chain relative to food quality and safety (Bendeković et al., 2015). In the Philippines, regulating food manufacturers, repackers and traders are done following the requirements of the Food Safety Act (2013) and the Revised Guidelines on Current Good Manufacturing Practice (cGMP) in Manufacturing, Packing, Repacking, or Holding Food (Admin Order No. 153, 2004). This is to ensure that foods available for the public are free from any 
contamination and adulteration that could cause harm to consumers. Relatively, the compliance to food safety management systems such as current Good Manufacturing Practices (cGMP) and Hazard Analysis and Critical Control Points (HACCP) is important not just to ensure food safety but likewise to reduce the risk of COVID-19 infection - a disease caused by a newly discovered coronavirus which primarily causes respiratory illnesses to those who are infected (Cucinotta \& Vanelli, 2020; Olaimat et al., 2020). Food safety standards are purposely designed and implemented as hygienic controls for compliance of Food Business Operators (FBOs). This is to ensure that contamination of foods by any disease-causing microorganisms can be minimized or prevented. As such, consumers will be protected against food-borne diseases (Admin Order No. 153, 2004).

Even before the pandemic, significant numbers of research (Chaoniruthisai et al., 2018; MayettMoreno \& Oglesby, 2018; Yapp \& Fairman, 2006) can be found from the literature about food safety compliance of various key players such as the food producers, manufacturers/processors, wholesalers, retailers and foodservice providers in the food chain, primarily to address the negative impacts of known foodborne illnesses. These research studies have identified challenges encountered by the food manufacturing enterprises in their compliance to food safety standards using surveys, interviews, document reviews of previous works in the field. From these studies, it can be noted that preventive controls like strict compliance to food safety protocols on hygienic food preparation to prevent the potential spread of pathogens have been recommended and given emphasis.

However, during the time of the pandemic, food safety concerns have drawn more significant attention not just to the consumers but also to those who manufacture, repack, resell, and trade food products. Producing a safe and reliable global food supply to prevent the transmission of the coronavirus is one of these concerns for processors, sellers, and consumers. Although, as to date, no scientific evidence yet proves that food packaging is a direct carrier or source of the transmission of coronavirus, some studies show evidence of the transmission of the virus through contact surfaces due to its ability to survive on these surfaces for several days (Olaimat et al., 2020). It has been likewise reported that the occurrence of coronavirus, just like other pathogens, is possible due to some food preparation practices and eating habits of consumers (S. Aday \& Aday, 2020).

Given the above relevance of food safety compliance and the recommended protocols against COVID-19, the importance of continuous assessment of the food safety compliance of FBOs can now be viewed from a more significant perspective. The positive effects of any effort or mitigation strategy, either voluntary or required, are related with the large extent to the ability and willingness of the individuals and organizations to adhere or comply. It is very important to comply with food safety standards to prevent foodborne illnesses regardless of how challenging the situation may become (Ligans et al., 2020). Thus, this study systematically investigates the extent to which the micro FBOs have complied with the food safety guidelines, their perceived challenges, and how their existing food safety compliance could impact the COVID-19 responses. Micro-FBOs, as used in this study are defined as food processors with less than 10 employees and capital of less than Php3,000,000.00.

The study specifically assesses the food safety compliance of micro FBOs in terms of contextual factors, control activities, and quality assurance activities which can be attributed to COVID-19 responses. Contextual factors include sanitary facilities, equipment, and utensils while control activities include sanitary operations, personnel 
hygiene, and process and controls. Moreover, it determines the challenges encountered by the micro FBOs in the implementation of the recommendations and the technical assistance they need. Finally, it provides the implications of food safety compliance of FBOs to the COVID-19 pandemic.

\subsection{Methodology}

This quantitative study utilized the descriptivecomparative research design to describe the food safety compliance, the challenges, and the technical needs of the micro-FBOs. It utilized the data and information gathered from the implementation of the Food Safety Consultancy Project for selected micro-FBOs in Central Luzon. The said consultancy project was implemented by one of the government agencies which likewise funded the project through the researchers as outsourced consultants from the university. This is in line with their effort to assist the micro-FBOs to comply with food safety requirements. The consultancy projects' design included the preassessment phase which is the initial stage of assessment, the intervention phase, and the final assessment phase.

\section{Respondents}

The study utilized purposive-homogenous sampling as the data and information used were gathered from the 15 pre-selected FBOs in Central Luzon, Philippines as beneficiaries of the Food Safety Consultancy Project. They were selected by the government agency that funded the projects following their set criteria. These FBOs are engaged in the production of native cakes and delicacies, bread and pastries, dried fruits and vegetables, peanut butter, turmeric powder, ready-to-drink juices, and meat products. All of which seek to improve their food safety system in compliance with GMPs. The FBOs served as the respondents during the interview and during the conduct of the food safety assessment and diagnosis. Production workers were likewise observed and interviewed.

\section{Research Instruments}

The researchers developed a food safety assessment form and interview guide questionnaires from the consultancy project as research instruments. The developed Food Safety Assessment Form (FSAF) instrument was based on the applicable requirements of Current Good Manufacturing Practice (cGMP) (Admin Order No.153, 2004). The FSAF consists of three sections. The first section covered the preliminary information such as the name of the business, focal person, product lines, and operation schedules, among others. The second part covered the different parameters to be assessed in each FBO relative to their food safety implementation. This part was composed of seven sections which were lifted from the applicable guidelines of the Admin Order No. 153 (2004). The first section focused on the requirements on plants and grounds wherein 11 specific parameters were noted. The succeeding sections covered the requirements on equipment and utensils, sanitary facilities, sanitary operations, personnel, hygiene, process and controls, and quality assurance with four (4), eight (8), six (6), five (5), nine (9) and four (4) specific parameters, respectively. These specific parameters for each section were likewise taken from the cGMP guidelines. Finally, the third part of the FSAF covered the shortlisted challenges. The shortlisting was based on the food industry practices and interventions of the researchers with other microFBOs. The FSAF was reviewed and validated by five food technologists with expertise in food safety inspection and implementation. 


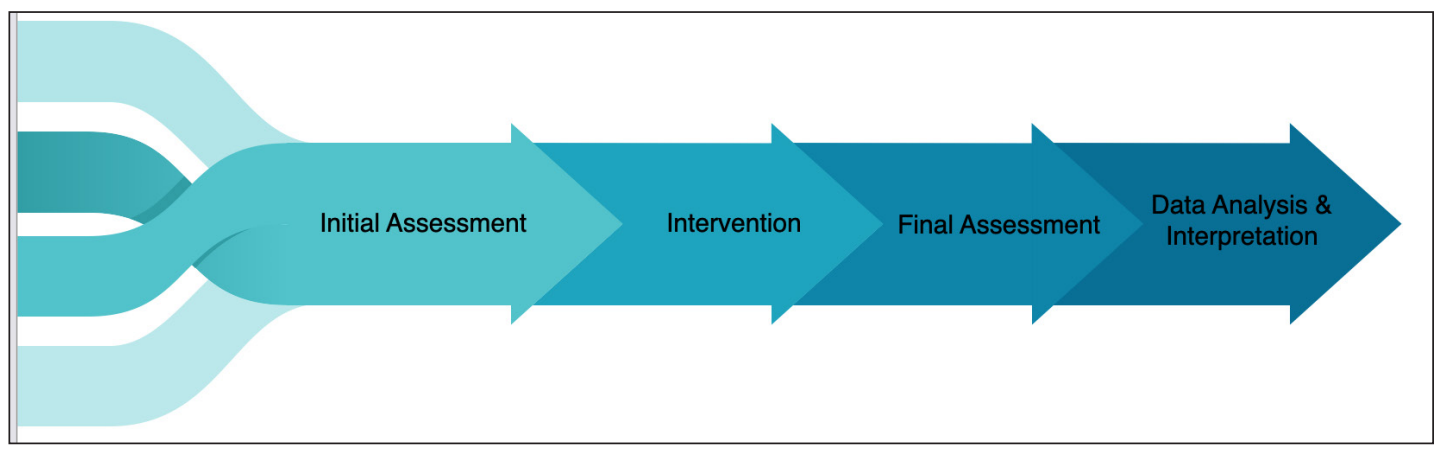

Figure 1. Schematic Diagram of the Research Procedure

The study comprised of two stages (Figure 1) of food safety assessment following the design of the consultancy project wherein the data and information were collected. After conducting the first assessment, an intervention program was implemented based on the findings to improve the micro-FBOs' compliance to food safety standards. After three months, the second assessment was conducted to determine any improvement in their compliance to the standards. The first assessment focused on the existing cGMP compliance and/or practices of the micro FBOs. This was done through a firm visit, observation, document review, and interview with the FBOs and their workers. Data were analyzed based on the requirements of CGMP. After which, the project team provided shortand long-term recommendations to the microFBOs through a written report that was based on the results of the initial food safety assessment. The short-term recommendations pertained to those that need immediate implementation and require minimal investment and time; which, if not implemented, the existing practices could contribute to the occurrence or increase the risk of food contamination or adulteration like a spread of pathogenic microorganisms and viruses in the food contact surfaces. These include but not limited to the proper application of cleaning and sanitation practices, $5 \mathrm{~S}$ and minor facility repairs, equipment layout, documentation of their food safety and quality assurance policies, programs, and procedures, generation of food safety and quality assurance records, and implementation of food safety monitoring protocols in the workplace. Whereas the long-term recommendations pertained to recommendations that may not need immediate implementation as they may require financial resources and/or other resources for compliance that can be difficult for the microenterprise to provide within the period of project implementation, which include constructions, major renovations of facilities and purchase of production equipment. In addition, scheduled coaching sessions were conducted to provide them with possible strategies and practical tips on implementing the recommendations. FBOs were also instructed to implement some additional actions related to the given recommendations as they find necessary. The second assessment phase was conducted after about three months from the conduct of the initial assessment based on the Terms of Reference of the project provided by the funding agency. The same tool and strategies in the initial stage of assessment were used. Also, during the second stage of the assessment, the researchers conducted interviews with the micro-FBOs to learn about the challenges they encountered in the implementation of the recommendations that were contributory to the status of their cGMP compliance. 


\section{Data Analysis and Statistical Treatment}

The data and information gathered from the two stages of food safety assessment and interviews were tabulated and analyzed. The results on the mean score of each parameter, under the different categories, on the first and second stages of assessment were subjected to paired samples T-test, at the .05 significance level, to identify whether a significant difference was evident on the status of their compliance. Aside from this, mean scores result for each area were interpreted using the following modified food safety diagnostic scoring system (Table 1) (Jacxsens et al., 2011; Luning et al., 2008; Luning et al., 2010). The interview responses on the challenges encountered and needed technical assistance by the micro FBOs were tallied using frequency percentage. Data and information gathered were further analyzed and discussed to highlight continuous relevance and impact to COVID-19 responses.

Table 1. Modified Food Safety Diagnostic Scoring System

\begin{tabular}{|c|c|c|c|c|c|c|}
\hline \multirow{2}{*}{$\begin{array}{l}\text { Mean } \\
\text { Score }\end{array}$} & \multirow{2}{*}{$\begin{array}{l}\text { Assigned } \\
\text { Score }\end{array}$} & \multicolumn{4}{|c|}{$\begin{array}{l}\text { Interpretation of } \\
\text { Assigned Score per cGMP Guidelines Category }\end{array}$} & \multirow{2}{*}{ Actions Needed } \\
\hline & & Contextual & $\begin{array}{l}\text { Control } \\
\text { activities }\end{array}$ & $\begin{array}{l}\text { Assurance } \\
\text { Activities }\end{array}$ & $\begin{array}{c}\text { System } \\
\text { Compliance }\end{array}$ & \\
\hline 0 & 0 & $\begin{array}{l}\text { Very High } \\
\text { risk }\end{array}$ & $\begin{array}{l}\text { Not } \\
\text { performed }\end{array}$ & $\begin{array}{l}\text { Not } \\
\text { performed }\end{array}$ & $\begin{array}{c}\text { None } \\
\text { Compliance }\end{array}$ & $\begin{array}{l}\text { Major Investment } \\
\text { /Provision } \\
\text { Needed }\end{array}$ \\
\hline $0.1-0.99$ & 1 & High risk & Basic level & Basic level & Low compliance & $\begin{array}{c}\text { Major } \\
\text { Improvement of } \\
\text { the existing }\end{array}$ \\
\hline $1.0-1.49$ & $1-2$ & $\begin{array}{l}\text { Moderately } \\
\text { high }\end{array}$ & $\begin{array}{l}\text { Basic } \\
\text {-Average }\end{array}$ & $\begin{array}{l}\text { Basic } \\
\text {-Average }\end{array}$ & $\begin{array}{l}\text { Moderately low } \\
\text { Compliance }\end{array}$ & $\begin{array}{c}\text { Major to } \\
\text { Moderate } \\
\text { Improvement of } \\
\text { the existing }\end{array}$ \\
\hline $1.50-2.00$ & 2 & Average risk & $\begin{array}{l}\text { Average } \\
\text { level }\end{array}$ & $\begin{array}{l}\text { Average } \\
\text { level }\end{array}$ & $\begin{array}{l}\text { Average } \\
\text { Compliance }\end{array}$ & $\begin{array}{l}\text { Moderate } \\
\text { Improvement of } \\
\text { the existing }\end{array}$ \\
\hline $2.01-2.49$ & $2-3$ & $\begin{array}{l}\text { Moderately } \\
\text { low }\end{array}$ & $\begin{array}{l}\text { Average- } \\
\text { Advanced }\end{array}$ & $\begin{array}{l}\text { Average- } \\
\text { Advanced }\end{array}$ & $\begin{array}{l}\text { Moderately high } \\
\text { compliance }\end{array}$ & $\begin{array}{l}\text { Minor } \\
\text { Improvement of } \\
\text { the existing }\end{array}$ \\
\hline $2.50-3.0$ & 3 & Low risk & $\begin{array}{c}\text { Advanced } \\
\text { Level }\end{array}$ & $\begin{array}{c}\text { Advanced } \\
\text { Level }\end{array}$ & high compliance & $\begin{array}{l}\text { Continual } \\
\text { Improvement of } \\
\text { the existing }\end{array}$ \\
\hline
\end{tabular}

\subsection{Results and Discussion}

\section{Food safety compliance of FBOs}

The food safety compliance of micro-FBOs in terms of equipment and utensils requirements has a mean score of $1.52(S D= \pm 0.44)$ at the initial assessment and $1.72(S D= \pm 0.57)$ on the final assessment, for all the parameters (Table 2).
This has been found not significant and suggests that all requirements have an average risk of compromising food safety and could negatively impact the response to COVID-19. The surfaces of utensils, packaging material, counter conveyor belts, interiors of transport vehicles, and all other food work stations, should always be given close 
attention as food handlers can act to impede the spread of COVID-19 ((Olaimat et al., 2020). Thus, micro-FBOs need to continue the improvement that they started to significantly elevate the level of their compliance and increase the positive impact on food safety and COVID-19 response.

On the other hand, the FBOs' compliance with sanitary facilities requirements was evaluated using eight specific parameters that are presented in Table 3. Analysis of data from the final assessment has revealed that there is a significant increase in the status of compliance on handwashing facility and water potability program implementation of the FBOs. This finding can have a positive re-enforcement to the health protocols against the spread of COVID-19. As cited by Olaimat et al. (2020), washing stations should be maintained for the workforce with the provision of normal soap, warm running water, hand sanitizers, and posters designed for displaying information regarding effective hand washing and sanitization as infected people may remain asymptomatic or be pre-symptomatic during the disease and may spread the infection.

However, in general, the results show no significant difference in the compliance of the FBOs to the other parameters under the area of sanitary facility requirements, such as effluent and waste disposal, water supply, toilets, changing facility, eating facility, and disinfection facility during the first and second assessment. These facilities are vital to prevent the possible spread acrosscontamination of pathogenic microorganisms like viruses. As such, their availability and proper maintenance could provide positive support to the prevention of COVID-19. Given these findings, there is a need to further improve the compliance of the micro-FBOs in the above areas of contextual factors and serve its purpose not just in attaining food safety but likewise to provide impact to COVID-19 response.

For the control activities, areas assessed covered the sanitary operations, personnel requirements, and process and controls which include several parameters. The mean score (Table 4) of the whole group is $1.23(\mathrm{SD}= \pm$ $0.13)$ at the initial assessment and $1.47(\mathrm{SD}= \pm$ 0.622) on the final assessment, wherein both mean scores are diagnosed to have a basic to average level of compliance to food safety on the sanitary operations aspect that requires major to moderate improvement of the existing control activities. Results of the final assessment suggest that there is a significant change observed in the compliance of micro-FBOs on the requirements on the documented SSOP or Work Instructions (WI) as these documents are readily available during the second stage of assessment. These documents, when implemented, are important to establish consistency and demonstrate effective cleaning and sanitation system in the workplace and could positively contribute to the prevention of the spread of pathogenic microorganisms and viruses to food contact surfaces and food handlers. However, the rest of the results show no significant difference in the compliance to facility maintenance and sanitation. It has been noted that the unsanitary condition of the facility was observed during the second assessment stage. Thus, in general, these results suggest that the control activities have a moderately high risk of compromising food safety. Major to moderate improvement of the existing practices and documentation is highly needed for it to positively impact not just the food safety compliance but likewise to COVID-19 response. 
Table 2. Paired Samples Statistics and t-Test Results for FBOs' Compliance to Equipment and Utensils Requirements $(N=15)$

\begin{tabular}{lcc}
\hline Equipment and Utensil Requirements & $\begin{array}{c}\text { Initial Assessment } \\
\text { (Mean } \pm \text { SD) }\end{array}$ & $\begin{array}{c}\text { Final Assessment } \\
\text { (Mean } \pm \text { SD) }\end{array}$ \\
\hline Equipment Condition & $1.93 \pm 0.53$ & $2.10 \pm 0.54$ \\
$\begin{array}{l}\text { Documented and Implemented } \\
\text { Equipment SSOP, WI, and Programs }\end{array}$ & $1.3 \pm 0.70$ & $1.57 \pm 0.82$ \\
Equipment Installation (least 2 meters) & $1.90 \pm 1.06$ & $1.93 \pm 1.05$ \\
$\begin{array}{l}\text { Equipment Calibration and Maintenance } \\
\text { Program and Records }\end{array}$ & $0.93 \pm 0.70$ & $1.30 \pm 0.96$ \\
Mean Score & $1.52 \pm 0.44$ & $1.72 \pm 0.57$ \\
Interpretation & Average Risk & Average Risk \\
\hline
\end{tabular}

Table 3. Paired Samples Statistics and t-Test Results for FBOs' Compliance to Sanitary Facilities Requirements ( $N=15)$

\begin{tabular}{lcc}
\hline Sanitary Facility Areas & $\begin{array}{c}\text { Initial Assessment } \\
\text { (Mean } \pm \text { SD) }\end{array}$ & $\begin{array}{c}\text { Final Assessment } \\
\text { (Mean } \pm \text { SD) }\end{array}$ \\
\hline Handwashing Facility & $1.63 \pm 0.44$ & $2.03 \pm 0.61$ \\
Effluent \& Waste Disposal & $1.90 \pm 0.66$ & $2.03 \pm 0.61$ \\
Water Supply & $2.13 \pm 0.91$ & $2.33 \pm 0.82$ \\
Water Potability Program Implementation & $1.17 \pm 1.06$ & $1.53 \pm 0.97$ \\
Eating Facility & $1.77^{*} \pm 1.32$ & $1.77^{*} \pm 1.32$ \\
Toilets & $1.5 \pm 1.8$ & $0.94 \pm 0.94$ \\
Changing Facility & $0.93 \pm 1.03$ & $1.30 \pm 1.19$ \\
Disinfection Facility & $1.27 \pm 0.94$ & $1.47 \pm 1.08$ \\
Mean Score & $1.54 \pm 0.43$ & $1.78 \pm 0.54$ \\
Interpretation & Average Risk & Average Risk \\
\hline
\end{tabular}

Table 4. Paired Samples Statistics and t-Test Results for FBOs' Compliance to Sanitary Operations Requirements. $(N=15)$

\begin{tabular}{lcc}
\hline Sanitary Operation Areas & $\begin{array}{c}\text { Initial Assessment } \\
\text { (Mean } \pm \text { SD) }\end{array}$ & $\begin{array}{c}\text { Final Assessment } \\
\text { (Mean } \pm \text { SD) }\end{array}$ \\
\hline Facility Maintenance and Sanitation & $1.80 \pm 0.53$ & $1.93 \pm 0.59$ \\
Documented and Implemented SSOP or WI & $1.23 \pm 0.68$ & $1.70 \pm 0.59$ \\
Cleaning and Sanitation Program & $1.27 \pm 0.78$ & $1.63 \pm 0.74$ \\
$\begin{array}{l}\text { Documented and implemented Pest Control } \\
\text { Program }\end{array}$ & $1.03 \pm 0.72$ & $1.17 \pm 0.79$ \\
$\begin{array}{lcc}\text { Chemical Material Safety Data Sheet (MSDS) } \\
\text { and FDA Certificate of Product Registration }\end{array}$ & $0.80 \pm 0.86$ & $0.90 \pm 0.97$ \\
$\begin{array}{l}\text { Mean Score } \\
\text { Interpretation }\end{array}$ & $1.23 \pm 0.13$ & $1.47 \pm 0.622$ \\
\hline
\end{tabular}


The micro-FBOs' compliance with personnel requirements was assessed using six specific parameters (Table 5). The mean scores of all parameters passed are $1.44(\mathrm{SD}= \pm 0.45)$ at the initial assessment and $1.82(\mathrm{SD}= \pm 0.66$ ) on the final assessment. The increase in the mean scores has changed the diagnosis from "basic to average level" to "average level" of compliance to food safety requirements. There is a significant difference, at the .05 significance level, in the mean scores of the two stages of assessment of the compliance of FBOs on the availability of updated medical records and health certificates of workers. The assurance that the workers are physically fit to work and free from contagious diseases is important in ensuring food safety. As cited by Olaimat et al., (2020), the COVID-19 virus can survive for up to 72 hours as a virion on inanimate objects after completing its life cycle in the body of an infected person. With this, when the respiratory discharges of the COVID-19 infected person contaminate the food, such food items can be a potential carrier, and if these foods are contacted by other individuals, the virus is more likely to gain entry to their respiratory epithelium when unsanitized hands touch the nose, eyes, and mouth. Hence, the compliance of workers to the minimum health requirements can positively impact the micro-FBOs' COVID-19 response. Therefore, workers shall always observe other safety protocols in the processing plant. These include the appropriate use of personal protective equipment and compliance to regular hand washing when exchanging goods, plus the use of hand sanitizers, wearing of masks and gloves, and the maintenance of at least six (6) feet between personnel are important practices to prevent the spread of the virus and other disease-causing microorganisms. The rest of the parameters observed have shown no significant difference between the two stages of assessment.

The micro-FBOs' compliance to process control requirements were assessed using six specific parameters that are presented in Table 6. Among these parameters, no significant difference has been noted on the mean scores from the initial and final assessments which suggest an "average level" of compliance to food safety requirements. This finding entails the need for moderate improvement of the existing control activities. Their basic level of compliance in the physical protection of food products from contamination and the production processes and controls requires a major improvement to positively impact not just the response to food safety but likewise the potential spread of the virus.

Finally, the compliance of micro-FBOs to quality assurance requirements during the first and final assessments has been found not significant (Table 7) which suggests an "average level" of compliance. This finding entails the need for a moderate improvement of the existing quality control and assurance activities. This is due to the lack of technical personnel who will manage and play the role of quality assurance (QA) function. With the absence of a QA personnel, the majority of documents required are lacking; and compliance with food safety standards are not consistently monitored. The same average level of compliance was observed in the monitoring and evaluation of critical control points like cooking, pasteurization, cooling and storage time, and temperature. Monitoring is done only visually and the use of applicable time and temperature measuring tools are not being practiced. This is very critical specifically in ensuring the attainment of the required temperature to arrest bacteria and viruses. 
Furthermore, the basic level of compliance in the acquisition of the needed Certificates of Analysis (COA) of materials, and microbiological analysis/program for finished products is likewise noted from both stages of assessment. Thus, a major to moderate improvement of the existing practices and documentation is highly needed to effectively obtain food safety and contribute to the prevailing responses against COVID-19.

Table 5. Paired Samples Statistics and t-Test Results for FBOs ' Compliance to Personnel Requirements $(\mathrm{N}=15)$

\begin{tabular}{|c|c|c|}
\hline Personnel Requirements & $\begin{array}{l}\text { Initial Assessment } \\
\quad(\text { Mean } \pm \text { SD) }\end{array}$ & $\begin{array}{l}\text { Final Assessment } \\
\quad(\text { Mean } \pm \text { SD) }\end{array}$ \\
\hline Disease Control Policy and Program & $1.53 \pm 0.72$ & $1.90 \pm 0.69$ \\
\hline $\begin{array}{l}\text { Availability of updated Medical Records and Health } \\
\text { Certificate of workers }\end{array}$ & $1.73 \pm 1.39$ & $2.17 \pm 1.25$ \\
\hline $\begin{array}{l}\text { Hygienic Practices (e.g. handwashing and sanitation; wearing } \\
\text { of appropriate working garments and hair restraints) }\end{array}$ & $1.23 \pm 0.42$ & $1.80 \pm 0.84$ \\
\hline $\begin{array}{l}\text { Personnel Food Safety Training Program (cGMP, Food Safety, } \\
\text { Food Protection, Food Hygiene, etc.) }\end{array}$ & $1.43 \pm 0.53$ & $1.77 \pm 0.75$ \\
\hline $\begin{array}{l}\text { Supervision and Monitoring of hygiene and sanitation } \\
\text { implementation }\end{array}$ & $1.27 \pm 0.46$ & $1.47 \pm 0.74$ \\
\hline Mean Score & $1.44 \pm 0.45$ & $1.82 \pm 0.66$ \\
\hline Interpretation & Basic to Average & Average Level \\
\hline
\end{tabular}

Table 6. Paired Samples Statistics and t-Test Results for FBOs' Compliance to Process Controls Requirements $(N=15)$

\begin{tabular}{lcc}
\hline Process and Control Requirements & $\begin{array}{c}\text { Initial Assessment } \\
\text { (Mean } \pm \text { SD) }\end{array}$ & $\begin{array}{c}\text { Final Assessment } \\
\text { (Mean } \pm \text { SD) }\end{array}$ \\
\hline Receiving and Inspection of Materials' quality & $1.50 \pm 0.422$ & $1.80 \pm 0.65$ \\
Production Processes \& Control & $1.13 \pm 0.48$ & $1.47 \pm 0.74$ \\
Warehousing and storage of materials & $1.57 \pm 0.58$ & $1.79 \pm 0.54$ \\
First-In-First-Out Policy Implementation & $1.75 \pm 0.43$ & $1.96 \pm 0.57$ \\
$\begin{array}{l}\text { Control of Non-conforming materials and products } \\
\text { (documented procedure) }\end{array}$ & $1.32 \pm 0.54$ & $1.39 \pm 0.63$ \\
ldentification and Segregation of Rejected materials and & $1.10 \pm 0.78$ & $1.17 \pm 0.86$ \\
products & & \\
Documented and implemented processing guide (Process & $1.87 \pm 0.81$ & $1.90 \pm 0.81$ \\
Flow, Work Instructions) & $1.50 \pm 0.63$ & $1.53 \pm 0.68$ \\
Label Compliance to FDA A.O. 2014-0030 & $2.27 \pm 0.70$ & $2.33 \pm 0.72$ \\
Physical protection of food products from contamination & $1.53 \pm 0.34$ & $1.67 \pm 0.42$ \\
Mean Score & Average Level & Average Level \\
\hline Interpretation & & \\
\hline
\end{tabular}


Table 7. Paired Samples Statistics and t-Test Results for FBOs' Compliance to Quality Assurance Requirements ( $N=15)$

\begin{tabular}{|c|c|c|}
\hline Quality Assurance Requirements & $\begin{array}{l}\text { Initial Assessment } \\
(\text { Mean } \pm \text { SD) }\end{array}$ & $\begin{array}{l}\text { Final Assessment } \\
(\text { Mean } \pm \text { SD) }\end{array}$ \\
\hline Certificate of Analysis (COA) of Materials & $0.70^{*} \pm 0.88$ & $0.70^{*} \pm 0.88$ \\
\hline $\begin{array}{l}\text { Monitoring of control parameters and limits ( } \mathrm{ng} \mathrm{pH} \text {, moisture } \\
\text { content, water activity, Brix salinity) }\end{array}$ & $1.23 \pm 0.42$ & $1.27 \pm 0.49$ \\
\hline $\begin{array}{l}\text { Monitoring and evaluation of Critical Control points (CCP) } \\
\text { (Baking, Freezing, Cooking, Pasteurization, Roasting, } \\
\text { Sterilization, etc.) }\end{array}$ & $1.03 \pm 0.40$ & $1.17 \pm 0.49$ \\
\hline $\begin{array}{l}\text { Microbiological Analysis /Program for Finished Products (at } \\
\text { least once a year) }\end{array}$ & $0.73^{*} \pm 1.03^{*}$ & $0.73^{*} \pm 1.03^{*}$ \\
\hline Mean Score & $0.91 \pm 0.31$ & $0.98 \pm 0.38$ \\
\hline Interpretation & Average Level & Average Level \\
\hline
\end{tabular}

\section{Challenges Encountered by the FBOs in the implementation of recommendations}

The results presented in Table 8 on the challenges encountered by the micro-FBOs reveal that all of them encountered a lack of technical knowledge on the conduct of quality control and quality assurance activities, time constraints on the preparation of documentary requirements due to the busy schedule of focal person and/ or personnel, and few to no technical personnel. Meanwhile, $93.33 \%$ of the micro-FBOs encountered the problem of a lack of technical know-how in the preparation of documentary requirements. According to them, there were interventions such as the conduct of training and seminars but still, the actual implementation of the knowledge gained from the interventions, specifically on the documentation, remains a challenge for them. Just like what happened during the actual project implementation, wherein specific recommendations were already provided, but still, statistically, no significant changes were noted on their compliance from the two stages of assessment mean scores for the areas of process and controls, quality assurance, quality management system, and sanitary operations requirements.

Moreover, $80 \%$ of the micro-FBOs encountered the problem of the lack of capability on personnel management or handling personnel. This reason can be highly associated with the results of compliance of the FBOs in the area of personnel requirements. While the analysis of the data show that there is a significant difference between the assessment mean scores from two stages of assessment in some areas, this, however, has provided only a minimal improvement on the compliance to the requirements as diagnosed from moderately high risk to average risk. From the follow-up interview, the micro-FBOs has shared their difficulties in the implementation of food safety policies and programs because most of their workers are their relatives and/or immediate family members. Furthermore, $70 \%$ of the micro-FBOs (5) lack financial resources, thus $33.33 \%$ of them opt to defer facility improvement and implementation of other recommendations. Generally, information gathered from the interview suggest that the provision of a more compliant facility is not yet a priority to most of the micro-FBOs. They also have the misconception that a bigger and high-end facility is one of the requirements for securing FDALTO, which is not the case. None of them are aware that the compliance on cGMP does not always require so many resources as it depends on the size 
and nature of the FBOs. Other related findings that they experienced are environmental concerns due to the poor location of a production facility (e.g. flooding due to riverside location, infestation due to nearby forages, etc.).

\section{Identified technical assistance needed by FBOs}

Based on the abovementioned findings, the study identifies other technical assistance needed by the micro-FBOs from concerned government agencies and universities to improve their food safety compliance. The common identified technical assistance noted from the analysis and interpretation of the micro-FBOs' responses are presented in Table 9.

It is good to note that the micro-FBOs are very much willing to comply and that they are very much aware of the implications of cGMP compliance on the sustainability of their food business, and as a significant contribution in combating the prevailing COVID-19. If and when, according to them, they will be given more specific information and interventions that are relevant and applicable to their small operation, they are very positive that they can improve their compliance and provide better implications in combatting the difficulties brought by the COVID-19 pandemic. Some of them have shared that trainings and seminars are helpful for them to gain additional knowledge; however, if they will not be further guided on how these acquired learnings or knowledge will be implemented, these will remain as principles only for them. Since what they have is general information only, they have the fear that the limited resources that they will invest for the implementation of the recommendations might just be forsaken. What they need according to them is a more customized intervention that could directly guide them on the proper implementation of this knowledge. This can be done using more simplified and applicable approaches considering the unique characteristics of microFBOs. Interventions like coaching and mentoring and immersions by practicing professionals who understand the background and nature of food operations are some of the strategies identified to help them out.

Table 8. Challenges Encountered by Micro Food Processing Enterprises in the Implementation of Recommendations ( $N=15)$

\begin{tabular}{lc}
\hline Challenges & Percentage (\%) \\
\hline 1. Lacks technical knowledge on the conduct of quality control and quality assurance & $100 \%$ \\
activities & $100 \%$ \\
2. Time constraints on the preparation of documentary requirements due to the busy & \\
schedule of focal person and/or personnel & $100 \%$ \\
3. Few to no technical personnel & $93.33 \%$ \\
4. Lacks technical knowledge on the preparation of documentary requirements & $80 \%$ \\
5. Lacks capability on personnel management/ handling insubordination of personnel & $73.33 \%$ \\
6. Lacks financial resources & $33.33 \%$ \\
7. Deferment of facility improvement and implementation of other recommendations due \\
to the limited space or plans/considers on building another or transferring the production \\
facility to another location
\end{tabular}


Table 9. Identified technical assistance needed by micro FBOs towards food safety compliance

1. Provision of more relevant information and interpretation of the cGMP requirements based on the nature of the operation of the micro-FBOs.

2. Application of more simplified strategies and techniques to practically implement the cGMP guidelines specifically on production facility construction and layout.

3. The customized and adaptive approach of capacity building on the preparation of documentary requirements for their FDA-LTO registration.

4. Capacitate managerial/ supervisorial personnel on personnel management for family business set-up through coaching sessions rather than public training.

5. Strategies on how FBOs can have a better appreciation of personnel on their important roles in complying with food safety regulatory requirements.

6. A longer period of consultancy projects relevant to food safety.

7. Financial aids /grants and accessibility.

\section{Implications to COVID-19 Pandemic}

The study unfolds the compliance of microFBOs to food safety requirements that provide positive and negative impacts in mitigating the spread of the COVID-19 virus. It identifies and describes the existing practices of micro-FBOs that need to be improved and need to be supported by government agencies. These findings promote awareness among micro-FBOs on their significant roles to positively contribute to the response against COVID-19. Moreover, micro-FBOs have realized the strengths and weaknesses of their existing food safety systems that are instrumental in response to COVID-19. The findings highlighted in the study, likewise, provide inputs to regulatory bodies to revisit existing guidelines and protocols on food safety monitoring among FBOs that will increase their contribution in mitigating the risk brought about by the COVID-19 pandemic. For the government agencies supporting FBOs on their food safety compliance, the challenges identified from this study provide bases for the development and improvement of relevant strategies and approaches in the delivery of their programs and services for $\mathrm{FBOs}$ to make them more responsive in addressing the effects of COVID -19 pandemic and increasing their compliance to food safety requirements.

\section{0 Conclusion}

The level of the food safety compliance of the micro-FBOs needs to be elevated to create more impact on COVID-19 response. Although the recommendations and interventions provided to $\mathrm{FBO}$ s have helped them to improve in some areas of their food safety compliance, there are still identified challenges and problems that need to be addressed for them to be more compliant. FBOs need continuous assistance and must be engaged more proactively as they work hand in hand with various government agencies in improving their food safety management system. Thus, government agencies may investigate and analyze further the underlying causes of the identified challenges and problems of FBOs. These may provide significant inputs for them to continuously innovate their strategies and approaches in assisting FBOs relative to sustaining their food safety management system and making them instrumental in mitigating the transmission of COVID-19. 


\section{Acknowledgment}

The authors would like to acknowledge the Tarlac State University Extension Services Office (TSU-ESO) and the College of Science Department of Food Technology, and the Department of Science and Technology (DOST 3) Region 3 as the implementing and funding agencies of the project, respectively.

\section{References}

Aday, S., \& Aday, M. S. (2020). Impacts of COVID-19 on food supply chain. Food Quality and Safety, 4(4), 167-180. https://doi.org/10.1093/fqsafe/ fyaa024

Bendeković, J., Naletina, D., \& Nola, I. (2015, November 18-19). Food safety and food quality in the supply chain [Conference session]. Trade Perspectives 2015: Innovations in Food Retailing Conference, University of Zagreb, Croatia. https://www.researchgate.net/ publication/324389840_Food_safety_and_ food_quality_in_the_supply_chain

Chaoniruthisai, P., Punnakitikashem, P., \& Rajchamaha, K. (2018). Challenges and difficulties in the implementation of a food safety management system in Thailand: $A$ survey of BRC certified food productions. Food Control, 93, 274-282. https://doi. org/10.1016/j.foodcont.2018.06.004

Cucinotta, D., \& Vanelli, M. (2020). WHO declares COVID-19 a pandemic. Acta Biomedica, 91(1), 157-160. https://doi.org/10.23750/abm. v91i1.9397

Admin Order No. 153. (2004). http://spsissuances. da.gov.ph/index.php/laws/10-spsregulations/administrative-order/635-dohadministrative-order-no-153

Food Safety Act of 2013, 15th Congress, 3rd Regular Session (2013). https://mirror.officialgazette. gov.ph/2013/08/23/republic-act-no-10611/

Garcia, S. N., Osburn, B. I., \& Jay-Russell, M. T. (2020). One health for food safety, food security, and sustainable food production. Frontiers in Sustainable Food Systems, 4(1), 1-9. https:// doi.org/10.3389/fsufs.2020.00001

Jacxsens, L., Luning, P. A., Marcelis, W. J., van Boekel, T., Rovira, J., Oses, S., Kousta, M., Drosinos, E., Jasson, V., \& Uyttendaele, M. (2011). Tools for the performance assessment and improvement of food safety management systems. Trends in Food Science and Technology, 22(SUPPL. 1), S80-S89. https:// doi.org/10.1016/j.tifs.2011.02.008

Liggans, G. L., Dutilly, D. K., Carrington-Liggans, K. J., Cartagena, M. B., Idjagboro, C. E., Williams, L. B., Lewis, G. R., Russell, M. B., Moore, V. S., \& Sudler, R., Jr. (2020). Interventions and compliance: How the response to COVID-19 reflects decades of retail food protection efforts. Journal of Agriculture, Food Systems, and Community Development, 10(1), 227-231. https://doi.org/10.5304/jafscd.2020.101.007

Luning, P. A., Bango, L., Kussaga, J., Rovira, J., \& Marcelis, W. J. (2008). Comprehensive analysis and differentiated assessment of food safety control systems: A diagnostic instrument. Trends in Food Science and Technology, 
19(10), 522-534. https://doi.org/10.1016/j. tifs.2008.03.005

Luning, P. A., Jacxsens, L., Jasson, V., Marcelis, W., Kussaga, J., Spiegel, M. Van der, Kousta, M., Osés, S., Rovira, J., Devlieghere, F., \& Uyttendaele, M. (2010). Tools to support the self-assessment of the performance of food safety management systems. In How to improve the food safety of yy products? (pp 31-43). Universidad de Burgos. https://biblio. ugent.be/publication/1169836

Mayett-Moreno, Y., \& Oglesby, J. M. L. (2018). Beyond food security: Challenges in food safety policies and governance along a heterogeneous agri-food chain and its effects on health measures and sustainable development in Mexico. Sustainability (Switzerland), 10(12). https://doi.org/10.3390/ su 10124755

Olaimat, A. N., Shahbaz, H. M., Fatima, N., Munir, S., \& Holley, R. A. (2020). Food safety during and after the era of COVID-19 pandemic. Frontiers in Microbiology, 11, (1854), 1-6. https://doi. org/10.3389/fmicb.2020.01854

United Nations. (2019). Growing at a slower pace, world population is expected to reach 9.7 billion in 2050 and could peak at nearly 11 billion around 2100. https://www.un.org/ development/desa/en/news/population/ world-population-prospects-2019.html

World Health Organization [WHO]. (2021). Estimating the burden of foodborne diseases. http://www.who.int/foodsafety/areas_work/ foodbornediseases/ferg/en/

Yapp, C., \& Fairman, R. (2006). Factors affecting food safety compliance within small and mediumsized enterprises: Implications for regulatory and enforcement strategies. Food Control, 17(1), 42-51. https://doi.org/10.1016/j. foodcont.2004.08.007 